\title{
Modeling and Optimization for Piercing Efficiency and Energy Consumption Based on Mean Value Substaged KELM-PLS and GA Method
}

\author{
Dong Xiao ${ }^{1,2}$ and Jichun Wang ${ }^{3}$ \\ ${ }^{1}$ State Key Laboratory of Synthetical Automation for Process Industries, Northeastern University, Shenyang 110004, China \\ ${ }^{2}$ Information Science and Engineering School, Northeastern University, Shenyang 110004, China \\ ${ }^{3}$ College of Science, Liaoning Industry University, Jinzhou 121000, China
}

Correspondence should be addressed to Dong Xiao; xiaodong@ise.neu.edu.cn

Received 17 March 2014; Revised 22 May 2014; Accepted 23 May 2014; Published 17 June 2014

Academic Editor: Jiuwen Cao

Copyright (C) 2014 D. Xiao and J. Wang. This is an open access article distributed under the Creative Commons Attribution License, which permits unrestricted use, distribution, and reproduction in any medium, provided the original work is properly cited.

\begin{abstract}
Piercing manufacture of seamless tubes is the process that pierces solid blank into tube hollow. Piercing efficiency and energy consumption are the important indexes in the production of seamless tubes. Piercing process has the multivariate, nonlinear, crosscoupling characteristics. The complex factors that affect efficiency and consumption make it difficult to establish the mechanism models for optimization. Based on the production process, this paper divides the piercing process into three parts and proposes the piercing efficiency and energy consumption prediction models based on mean value staged KELM-PLS method. On the basis of mean value staged KELM-PLS prediction model, the minimum piercing energy consumption and maximum piercing efficiency are calculated by genetic optimization algorithm. Simulation and experiment prove that the optimization method based on the piercing efficiency and energy consumption prediction model can obtain the optimal process parameters effectively and also provide reliable evidences for practical production.
\end{abstract}

\section{Introduction}

In the production of seamless tube, the rotary reheating is the last working procedure of piercing production process. The tandem rolling production is the next working procedure of piercing production process. They both have higher production efficiency than piercing production process. So, the increase of production piercing efficiency plays a very important role in increasing the efficiency of overall production of seamless tube. Because the factors of affecting the piercing efficiency are rather complicated, it is difficult to build the mechanism model to find out its accurate value. Although the literature [1] analyzes the influence of parameters of piercing production process such as the rotational speed of guide disc and the rotational speed of roll, on the piercing efficiency, it only analyzes the influence of every parameter on the production efficiency statically and singly. Li [2] builds the model of relationship between the piercing efficiency and the wall thickness of shell. Although the literature $[3,4]$ analyzes the influence of technological parameters such as the percent reduction of roll, the angle of inclination of roll, the rotational speed of roll, and the rotational speed of guide disc, on the piercing energy consumption production, it does not give the comprehensive relational model. The literature [5] analyzes the influence of shape of piercing head on the piercing energy consumption. The literature [6] introduces modeling and optimization for piercing energy consumption, but it did not make a comprehensive consideration for piercing energy consumption and piercing efficiency. The literature [7] introduces a modeling and optimization method for piercing energy consumption and piercing efficiency, but the model is linear which limits the accuracy of model prediction and the results of optimization. By the research for the production practice and the literature, it can be known that the main factors which affect the piercing efficiency include the rotational speed of roll, the percent reduction of roll, the rotational speed of guide disc, the size of tube blank and shell, the temperature of tube blank, and the feed angle of 
roll. Because the state pays more and more close attention to the iron and steel industry with high energy consumption, every seamless tube manufacturer attaches more importance to the piercing energy consumption. Although to reduce the piercing energy consumption can meet the requirements of the direction of policy of the state and can also reduce the production cost of piercing, it may reduce the production efficiency. By the comprehensive consideration of all kinds of literatures and the actual production situations, this paper draws the following conclusion: the main production process parameters affecting the piercing energy consumption include the rotational speed, the percent reduction and the angle of inclination of roll, the size of tube blank and shell, the rotational speed of guide disc, and the temperature of tube blank.

In accordance with the characteristics of actual production of piercing process of tube blank, its working process can be divided into three substages: the primary unstable piercing (the first stage), the stable piercing (the second stage), and the secondary unstable piercing (the third stage), as shown in Figure 1. Through the analysis and comparison of the production process and data, it is found that the influences of different process parameter variables in the different piercing stages on the piercing efficiency and energy consumption are different. On this basis, we propose mean value substaged KELM-PLS method for the prediction of piercing efficiency and piercing energy consumption. This method selects the influence variable of process according to the piercing production stage, and the average value of corresponding variables in this stage is used as the input value. It overcomes the following shortcomings of traditional modeling method that the structure is complicated, the number of variables is larger, and the amount of calculation is considerable, and so forth. Finally, by the simulation inspection of the actual production data, the accuracy and rapidity of the introduced method are verified. After the modeling obtains the prediction model of accurate piercing efficiency and energy consumption, the optimum algorithm is utilized to carry out the comprehensive optimization of piercing efficiency and energy consumption on the basis of the model. This paper adopts the GA (genetic algorithm) [8-10]. The algorithm is a simple, fast, accurate, and effective global optimum algorithm. The algorithm can obtain the optimum production process parameters under specified conditions, which can be used to guide the actual production, in order to obtain the maximum economic benefit.

\section{A Summary of Piercing Efficiency and Energy Consumption}

The piercing efficiency of seamless tube is also called the axial sliding friction coefficient, which is the ratio of theoretical pure rolling time $t_{\mathrm{th}}$ to the actual pure rolling time $t_{\mathrm{ac}}$, as shown in the formula,

$$
y=\frac{t_{\mathrm{th}}}{t_{\mathrm{ac}}}
$$

In the formula, $y$ is the piercing efficiency, $\%$; $t_{\text {th }}$ is the theoretical pure rolling time, $s$; and $t_{\mathrm{ac}}$ is the actual pure rolling time, $s$.

The main factors to affect the piercing efficiency include the rotational speed of roll, size, the shape and quality of material of tool, the size of tube blank, the size of shell, the feed angle, the temperature of tube blank, and the deformation system. The actual pure rolling time $t_{\mathrm{ac}}$ is measured directly by the field sensor, and the theoretical pure rolling time $t_{\text {th }}$ can be expressed as the following formula:

$$
t_{\text {th }}=\frac{l+L}{\left(\pi D_{c} n_{r} / 60\right) \sin \alpha} .
$$

In the formula, $n_{r}$ is the rotational speed of roll, $\mathrm{r} / \mathrm{min} ; \alpha$ is the feed angle, rad; $D_{1}$ is the average diameter of roll, $\mathrm{m}$; $l$ is the length of deformed zone, $\mathrm{m}$; and $L$ is the length of shell, $\mathrm{m}$. Because the manifestation of deformed zone is completely backward slip, $t_{\mathrm{ac}}$ is more than $t_{\mathrm{th}}$ all the time, and there is $y \leq 1$ all the time.

The piercing energy consumption can be calculated by using the energy consumption produced in the course of piercing production of a steel tube. It can be found out by accumulating the electric energy consumed in producing this steel tube. The concrete expression is as the following:

$$
E=\int_{t_{0}}^{t_{1}} P_{\text {piercing }} d t=\int_{t_{0}}^{t_{1}} U_{\text {piercing }} I_{\text {piercing }} d t
$$

In the formula, $E$ is the piercing energy consumption, J; $U_{\text {piercing }}$ is the operating voltage of piercing, $\mathrm{V} ; I_{\text {piercing }}$ is the working current of piercing, $\mathrm{A} ; t_{0}$ is the starting time of piercing, $\mathrm{s}$; and $t_{1}$ is the end time of piercing, $\mathrm{s}$.

\section{Analysis of Modeling Variables and Data Preprocessing}

This paper firstly researches and analyzes the factor variables that affect the piercing efficiency and energy consumption. It is found in the research that some production variables affect the final piercing efficiency and energy consumption all the time and some production variables affect a part of the production stage only. The modeling variables of piercing efficiency and energy consumption obtained by the comprehensive comparison are shown in Table 1.

When building the model of efficiency and piercing energy consumption on the basis of mean value substaged KELM-PLS method, the average value of the modeling data is evaluated firstly. The average value of the data variables in three piercing stages is evaluated, respectively, and then the three-dimensional data is changed into the two-dimensional data. For the modeling data of piercing efficiency, the vector $\left[x_{1,1}, x_{1,2}, \ldots, x_{1,9}, x_{2,1}, x_{2,2}, \ldots, x_{2,10}, x_{3,1}, x_{3,2}, \ldots, x_{3,9}\right]$ formed by 28 variables can be obtained after it is changed into the two-dimensional data. For the modeling data of piercing energy consumption, the vector $\left[x_{1,1}^{\prime}, x_{1,2}^{\prime}, \ldots, x_{1,6}^{\prime}, x_{2,1}^{\prime}, x_{2,2}^{\prime}, \ldots, x_{2,9}^{\prime}, x_{3,1}^{\prime}, x_{3,2}^{\prime}, \ldots, x_{3,8}^{\prime}\right]$ formed by 23 variables can be obtained after it is changed into the two-dimensional data. The data matrix $X(I \times 28)$ of 
TABLE 1: Modeling variable table for piercing efficiency and energy.

\begin{tabular}{|c|c|c|c|c|c|c|c|c|}
\hline \multirow[b]{2}{*}{ Number } & \multirow{2}{*}{$\begin{array}{l}\text { Original } \\
\text { variables }\end{array}$} & \multicolumn{2}{|c|}{ The first stage variables } & \multicolumn{2}{|c|}{ The second stage variables } & \multicolumn{2}{|c|}{ The third stage variables } & \multirow[b]{2}{*}{ The mean of variables } \\
\hline & & Efficiency & $\begin{array}{c}\text { Energy } \\
\text { consumption }\end{array}$ & Efficiency & $\begin{array}{c}\text { Energy } \\
\text { consumption }\end{array}$ & Efficiency & $\begin{array}{c}\text { Energy } \\
\text { consumption }\end{array}$ & \\
\hline 1 & $x_{1}$ & $x_{1,1}$ & $x_{1,1}$ & $x_{2,1}$ & $x_{2,1}$ & $x_{3,1}$ & $x_{3,1}$ & $\begin{array}{l}\text { The percent reduction of upper } \\
\text { roll }\end{array}$ \\
\hline 2 & $x_{2}$ & $x_{1,2}$ & $x_{1,2}$ & $x_{2,2}$ & $x_{2,2}$ & $x_{3,2}$ & $x_{3,2}$ & $\begin{array}{l}\text { The percent reduction of under } \\
\text { roll }\end{array}$ \\
\hline 3 & $x_{3}$ & $x_{1,3}$ & $x_{1,3}$ & $x_{2,3}$ & $x_{2,3}$ & $x_{3,3}$ & $x_{3,3}$ & $\begin{array}{l}\text { The angle of inclination of } \\
\text { upper roll }\end{array}$ \\
\hline 4 & $x_{4}$ & $x_{1,4}$ & $x_{1,4}$ & $x_{2,4}$ & $x_{2,4}$ & $x_{3,4}$ & $x_{3,4}$ & $\begin{array}{l}\text { The angle of inclination of } \\
\text { under roll }\end{array}$ \\
\hline 5 & $x_{5}$ & $x_{1,5}$ & $x_{1,5}$ & $x_{2,5}$ & $x_{2,5}$ & $x_{3,5}$ & $x_{3,5}$ & $\begin{array}{l}\text { The rotational speed of upper } \\
\text { roll }\end{array}$ \\
\hline 6 & $x_{6}$ & $x_{1,6}$ & $x_{1,6}$ & $x_{2,6}$ & $x_{2,6}$ & $x_{3,6}$ & $x_{3,6}$ & $\begin{array}{l}\text { The rotational speed of under } \\
\text { roll }\end{array}$ \\
\hline 7 & $x_{7}$ & $x_{1,7}$ & & & & & & $\begin{array}{l}\text { The position change range of } \\
\text { pusher }\end{array}$ \\
\hline 8 & $x_{8}$ & $x_{1,8}$ & & & & & & $\begin{array}{l}\text { The actual position of mandrel } \\
\text { thrust block }\end{array}$ \\
\hline 9 & $x_{9}$ & $x_{1,9}$ & & $x_{2,7}$ & & $x_{3,7}$ & & The position of mandrel \\
\hline 10 & $x_{10}$ & & & $x_{2,8}$ & $x_{2,7}$ & $x_{3,8}$ & $x_{3,7}$ & $\begin{array}{l}\text { The rotational speed of left } \\
\text { guide disc }\end{array}$ \\
\hline 11 & $x_{11}$ & & & $x_{2,9}$ & $x_{2,8}$ & $x_{3,9}$ & $x_{3,8}$ & $\begin{array}{l}\text { The rotational speed of left } \\
\text { guide disc }\end{array}$ \\
\hline 12 & $x_{12}$ & & & $x_{2,10}$ & $x_{2,9}$ & & & The temperature of tube blank \\
\hline
\end{tabular}

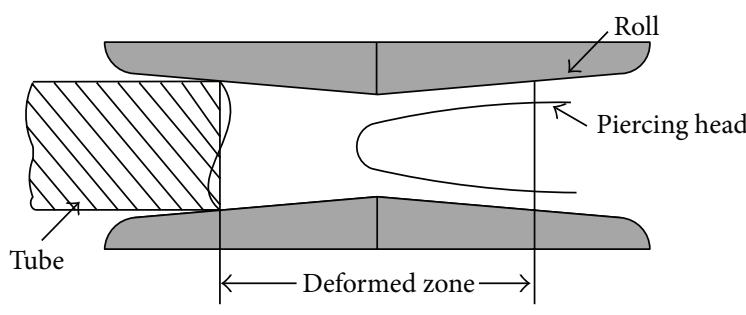

(a) The start of the primary unstable piercing stage

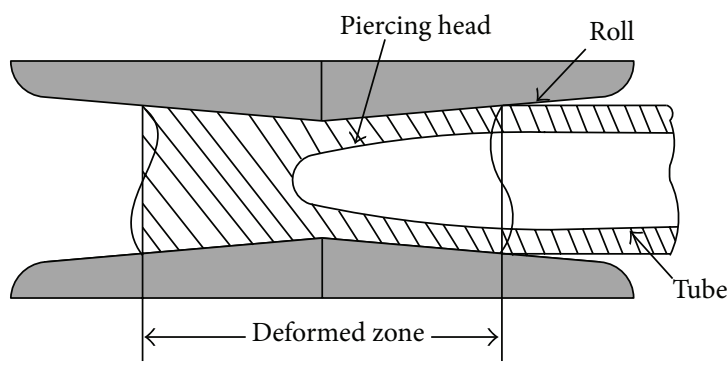

(c) The end of the stable piercing stage

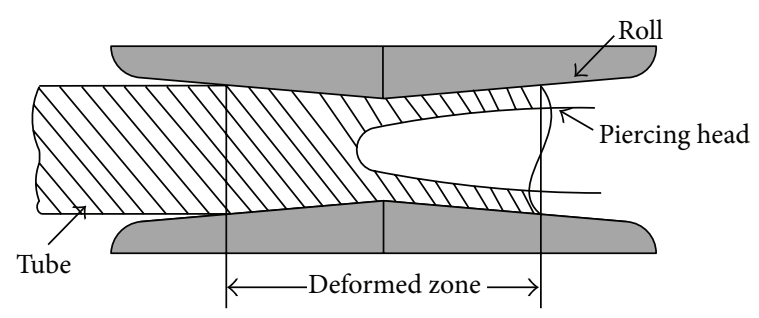

(b) The end of the primary unstable piercing stage

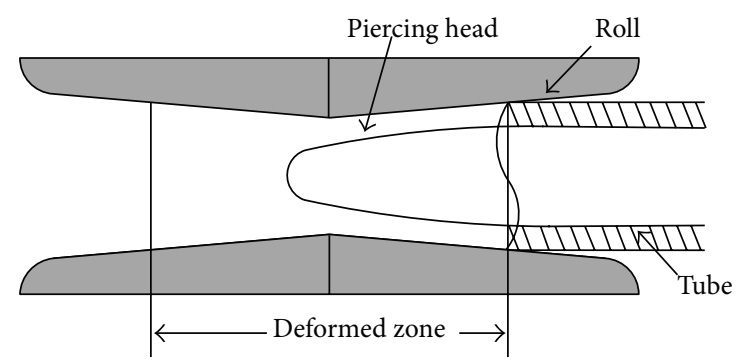

(d) The end of the secondary unstable piercing stage

FIGURE 1: Definition of the parts for piercing process. 


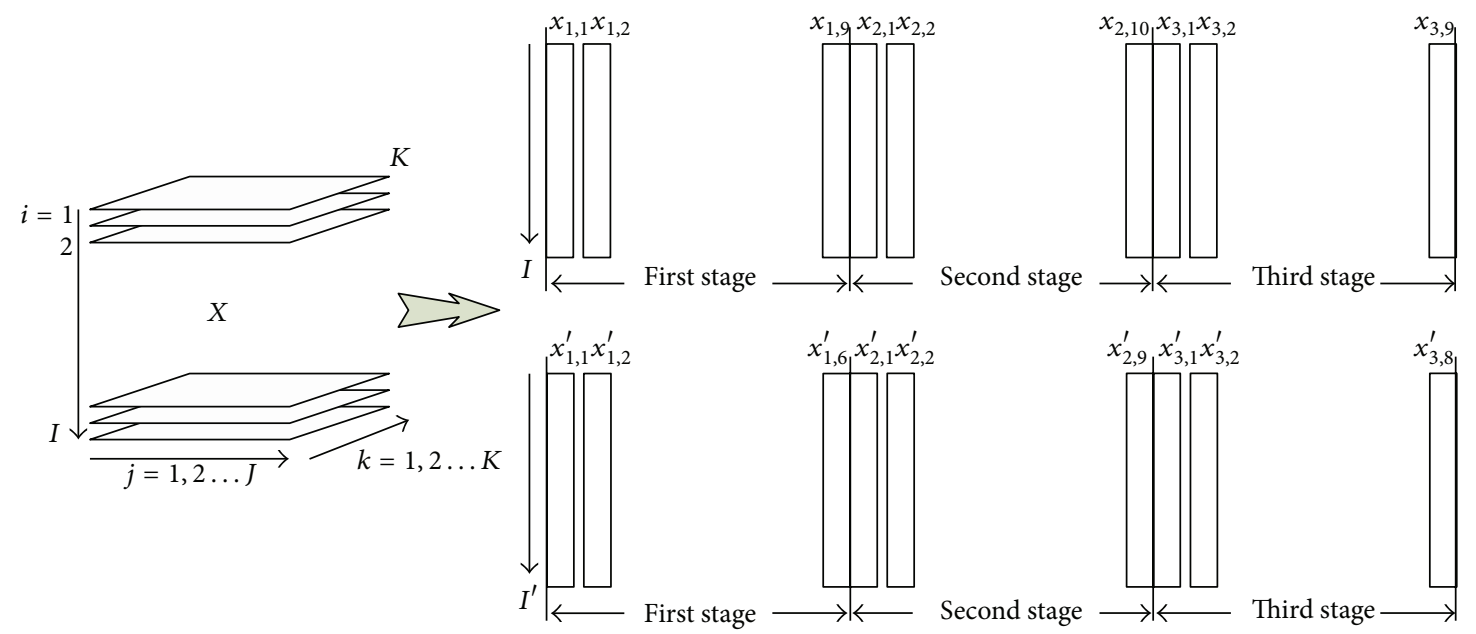

FIGURE 2: Unfolding of process data of three dimensions.

piercing efficiency and the data matrix $X^{\prime}\left(I^{\prime} \times 23\right)$ of piercing energy consumption shown in Figure 2, which considers $I$ production batches, are obtained.

\section{Building of Prediction Model Based on Mean Value Substaged KELM-PLS}

4.1. Nonlinear PLS. Since linear PLS (partial least squares) model cannot describe correctly the nonlinear relation between independent variable $X$ and dependent variable $Y$, nonlinear PLS method is required to solve this issue. Wold et al. extended the PLS method to nonlinear field [11, 12]. There are two feasible methods in nonlinear PLS methods: one is to perform array extension for input matrix, introduce some nonlinear terms of original variable, for example, the square term, and then regress the extended input and output matrix using PLS method. If prior knowledge on the relation of original input variable does not exist, this method cannot guide the selection of combined mode and may lead to oversized dimension of input matrix and the difficulties of processing; the other is to reserve the linear external model of PLS method. Internal model is nonlinear.

(1) External relation model is as follows:

$$
\begin{aligned}
& X=T P^{T}+E=\sum_{a=1}^{A} t_{a} p_{a}^{T}+E, \\
& Y=U Q^{T}+F=\sum_{a=1}^{A} u_{a} q_{a}^{T}+F,
\end{aligned}
$$

where $A$ is the number of reserved eigenvectors, $t_{a}(n \times 1)$ and $u_{a}(n \times 1)$ are the score vectors of $X$ and $Y$, respectively, $p_{a}(m \times$ 1) and $q_{a}(p \times 1)$ are the load vectors of $X$ and $Y$, respectively, $T(n \times A)$ and $U(n \times A)$ are the score matrices of $X$ and $Y$, respectively, $P(m \times A)$ and $Q(p \times A)$ are the load matrices of $X$ and $Y$, respectively, and $E$ and $F$ are the fit residual matrices of $X$ and $Y$, respectively.
(2) Internal relation model is as follows:

$$
\widehat{u}_{a}=f\left(t_{a}\right)+\varepsilon,
$$

where $f(\cdot)$ is the nonlinear function and $\varepsilon$ is the residual.

The internal model of PLS method adopts neural network gains extensive application because neural network has the capability of fitting nonlinearity. As traditional feedforward neural network adopts gradient learning algorithm during training, parameters in network need iteration and update. Not only the training time lasts long but also it easily results in the issues of local minimum and excessive training [13].

4.2. KELM Algorithm. In supervised batch learning, the learning algorithms use a finite number of input-output samples for training [14-18]. For $N$ arbitrary distinct samples $\left(x_{i}, t_{i}\right) \in R^{n} \times R^{m}$, where $x_{i}$ is a $n \times 1$ input vector and $t_{i}$ is a $m \times 1$ target vector, if an SLFN (single-hidden layer feedforward neural network [19-24]) with $\widetilde{N}$ hidden nodes can approximate these $N$ samples with zero error, it then implies that there exists $\beta_{i}, a_{i}$, and $b_{i}$, such that

$$
f_{\widetilde{N}}\left(x_{j}\right)=\sum_{i=1}^{\widetilde{N}} \beta_{i} G\left(a_{i}, b_{i}, x_{j}\right)+\varepsilon_{j}=t_{j}
$$

where $j=1, \ldots, N, a_{i}$, and $b_{i}$ are the learning parameters of hidden nodes (weight vector connecting the input node to the hidden node and threshold of the hidden node) which are randomly selected according to the proof given by Huang et al. and $\beta_{i}$ is the weight connecting the $i$ th hidden node to the output node. To avoid overfitting the noise in the data, an error term $\varepsilon_{j}$ is added. $G\left(a_{i}, b_{i}, x\right)$ is the output of the $i$ th hidden node with respect to the input $x$ and $\widetilde{N}$ the number of hidden nodes which can be determined by trial and error or prior expertise. Then, equation can be written compactly as

$$
H \beta=T,
$$


where

$$
\begin{gathered}
H\left(a_{1}, \ldots, a_{\widetilde{N}}, b_{1}, \ldots, b_{\widetilde{N}}, x_{1}, \ldots, x_{N}\right) \\
=\left[\begin{array}{ccc}
G\left(a_{1}, b_{1}, x_{1}\right) & \cdots & G\left(a_{\widetilde{N}}, b_{\widetilde{N}}, x_{1}\right) \\
\vdots & \cdots & \vdots \\
G\left(a_{1}, b_{1}, x_{N}\right) & \cdots & G\left(a_{\widetilde{N}}, b_{\widetilde{N}}, x_{N}\right)
\end{array}\right]_{N \times \widetilde{N}}, \\
\beta=\left[\begin{array}{c}
\beta_{1}^{T} \\
\vdots \\
\beta_{\widetilde{N}}^{T}
\end{array}\right]_{\widetilde{N} \times m}, \\
\end{gathered}
$$

where $H$ is called the hidden layer output matrix of the network; the $i$ th column of $H$ is the $i$ th hidden node's output vector with respect to inputs $x_{1}, x_{2}, \ldots, x_{N}$, and the $j$ th row of $H$ is the output vector of the hidden layer with respect to input $x_{j}$. The hidden node parameters $a_{i}$ and $b_{i}$ need not be tuned during training and may simply be assigned with random values. Equation (7) then becomes a linear system and the output weights $\beta$ are estimated as

$$
\widetilde{\beta}=H^{+} T,
$$

where $\mathrm{H}^{+}$is the Moore-Penrose generalized inverse of the hidden layer output matrix $H$ [25-29].

Function $g(\cdot)$ is usually unknown; we can incorporate kernel functions in $g(\cdot)$ [30]. KELM (kernel extreme learning machine) can solve the problem of random initialization of ELM algorithm, and learning parameters of the model have a good Reuben [31]. It can improve the performance and accuracy of model prediction of piercing efficiency and piercing energy consumption. The kernel matrix $K=$ $\left[K\left(x ; x_{1}\right), \ldots, K\left(x ; x_{N}\right)^{T}\right](K(\cdot)$ is the kernel function) is introduced into (9) to estimate the output of the KELM:

$$
\mathrm{o}=K T \text {. }
$$

Herein, the Gaussian kernel function (RBF) is adopted:

$$
K\left(x_{1} ; x_{2}\right)=\exp \left(-\lambda\left\|x_{1}-x_{2}\right\|^{2}\right),
$$

where $\lambda$ needs to be specified.

4.3. Mean Value Substaged KELM-PLS Modeling Steps. The difference of nonlinear PLS modeling method based on KELM from linear PLS method is that it uses KELM to establish internal nonlinear model and in the meantime achieve the update of internal and external models. This method reserves linear external model, extracts through PLS the attributive information of process, eliminates the colinearity of data, reduces the dimension of input variable, adopts KELM to establish nonlinear internal model between input score vector matrix and output score vector, and raises the nonlinear processing capability of internal model. Thus, KELM-PLS method has the advantages of PLS and KELM, that is, the characteristics of robustness and feature extraction of PLS method and quick nonlinear processing capability of KELM.
The modeling and testing steps of nonlinear PLS method based on KELM are as follows.

(1) Assign two standardized data matrices, $X \in R^{n \times m}$ and $Y \in R^{n \times p}$; dynamic nonlinear PLS regression model can be expressed as follows:

$$
\mathbf{X}=\left[\mathbf{x}_{1}, \mathbf{x}_{2}, \ldots, \mathbf{x}_{p}\right] .
$$

(2) Deploy the batch data of batch process, use crossvalidation method to determine the number of latent variable, and adopt linear PLS method to calculate the score vector matrices $T$ and $U$ and load vector matrices $P$ and $Q$ for modeling sample $X$ and $Y$.

Consider

$$
\begin{aligned}
& X=T P^{T}+E=\sum_{a=1}^{A} t_{a} p_{a}^{T}+E, \\
& Y=U Q^{T}+F=\sum_{a=1}^{A} u_{a} q_{a}^{T}+F .
\end{aligned}
$$

(3) Assign the node number of ELM hidden layer and activation function (e.g., sigmoid function), use ELM to establish nonlinear model between internal models $T$ and $U$, and gain $U=f_{\mathrm{KELM}}(T)$, where $f_{\mathrm{KELM}}(\cdot)$ is the nonlinear function indicated by KELM. Hidden nodes in a SLFN transform feature space into another feature space. The original ELM defines the number of nodes as a parameter to be defined. We increase the number of hidden nodes until reaching a stop criteria (ex. residual error reduction), meanwhile, the number of hidden nodes is less than $N$.

(4) Use testing data to check model precision. Conduct PLS decomposition on the testing data $X_{2}$, gain score vector $T_{2}$ :

$$
X_{2}=T_{2} P^{T}+E
$$

Introduce $T_{2}$ into KELM model, gain $U_{2}=f_{\text {KELM }}\left(T_{2}\right)$, and find out model prediction value through $\widehat{Y}=U Q^{T}$.

(5) The KELM-PLS method is used to build the prediction model of piercing efficiency and energy consumption for the data which is dealing with mean value substaged method according to Figure 2 and Table 1, and the model structure is shown in Figure 3.

The regression model between the data matrix $X$ of piercing efficiency and the prediction value $\hat{\mathbf{y}}$ of piercing efficiency, which can be obtained by mean value substaged KELM-PLS method, is formula (15), and in the same way, the relational model between the data matrix $X^{\prime}$ of piercing energy consumption and the prediction value $\widehat{\mathbf{y}}^{\prime}$ of piercing 


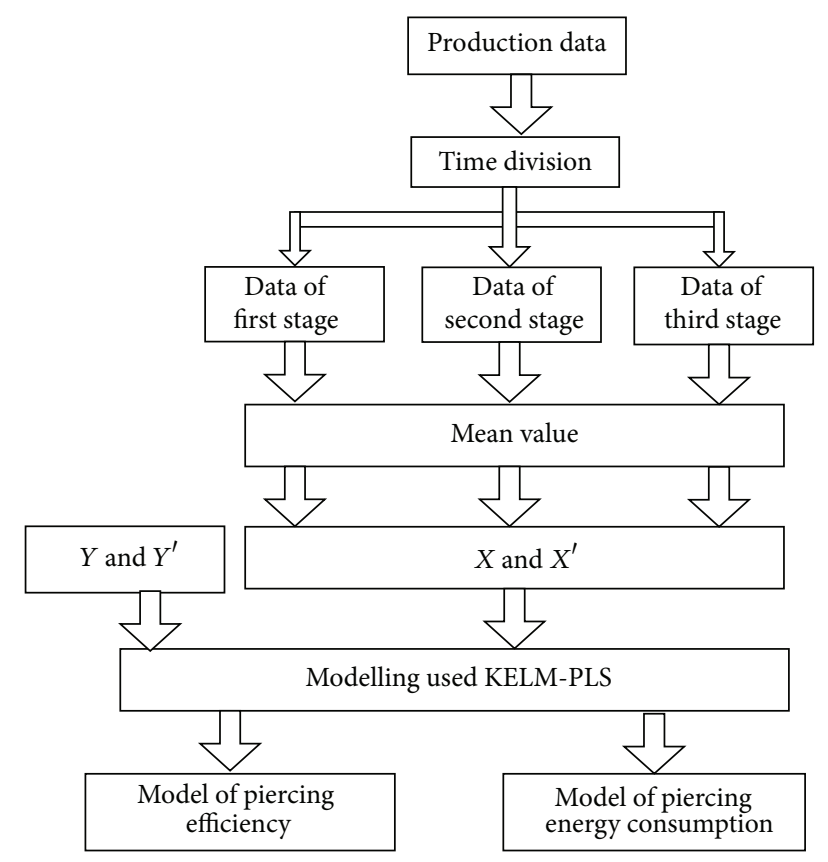

FIGURE 3: Chart of piercing efficiency and piercing energy model.

energy consumption, which can be obtained by substaged KELM-PLS method, is formula (16):

$$
\begin{aligned}
\widehat{\mathbf{y}} & =\mathbf{f}(\mathbf{X}, \boldsymbol{\theta}) \\
& =f\left(\left[x_{1,1}, x_{1,2}, \ldots, x_{1,9}, x_{2,1}, x_{2,2}, \ldots, x_{2,10},\right.\right. \\
& \left.\left.x_{3,1}, x_{3,2}, \ldots, x_{3,9}\right], \boldsymbol{\theta}\right), \\
\hat{\mathbf{y}}^{\prime} & =\mathbf{f}\left(\mathbf{X}^{\prime}, \boldsymbol{\theta}^{\prime}\right) \\
& =f\left(\left[x_{1,1}^{\prime}, x_{1,2}^{\prime}, \ldots, x_{1,6}^{\prime}, x_{2,1}^{\prime}, x_{2,2}^{\prime}, \ldots, x_{2,9}^{\prime},\right.\right. \\
& \left.\left.x_{3,1}^{\prime}, x_{3,2}^{\prime}, \ldots, x_{3,8}^{\prime}\right], \boldsymbol{\theta}^{\prime}\right) .
\end{aligned}
$$

Among them, $\boldsymbol{\theta}$ and $\boldsymbol{\theta}^{\prime}$ are the regression coefficients of model of piercing efficiency and energy consumption obtained by utilizing mean value substaged KELM-PLS.

\section{Comprehensive Optimization of Piercing Efficiency and Energy Consumption on the Basis of Genetic Algorithm}

After building the accurate model, we put the model into the objective function and utilize the genetic algorithm to optimize and find out the optimal production process parameters according to the different conditions of market and production, in order to guarantee the maximum profit of enterprise.

5.1. Decision Variable and Optimization Objective of Piercing Efficiency and Energy Consumption. For the upper roll and lower roll and left guide disc and right guide disc, although their real time parameters of actual production are different, the setting values to be controlled are set to the same setting values, and, therefore, they have merged into one production parameter in optimization when carrying out the optimization. As shown in Table 2, the decision variables related to the piercing efficiency are $\bar{x}_{1}, \bar{x}_{2}, \ldots, \bar{x}_{17}$, and the decision variables related to the piercing energy consumption are $\bar{x}_{1}, \bar{x}_{2}, \bar{x}_{3}, \bar{x}_{7}, \bar{x}_{8}, \bar{x}_{9}, \bar{x}_{10}, \bar{x}_{12}, \bar{x}_{13}, \bar{x}_{14}, \bar{x}_{15}, \bar{x}_{17}$. Their constraint conditions are formulas (18) (22) and the concrete change range is as follows: the temperature of tube blank: $1200 \sim 1300^{\circ} \mathrm{C}$, the rotational speed of guide disc: $20 \sim 30 \mathrm{r} / \mathrm{min}$, the actual position of mandrel thrust block: $115 \sim 170 \mathrm{~mm}$, the position change range of pusher: $0 \sim 2550 \mathrm{~mm}$, the position of mandrel: $200 \sim 300 \mathrm{~mm}$, the rotational speed of roll: 105 $195 \mathrm{r} / \mathrm{min}$, the angle of inclination of roll: $10 \sim 14^{\circ} \mathrm{mm}$, and the percent reduction of roll: $120 \sim 170 \mathrm{~mm}$. In order to obtain the maximum profit of production, it is necessary to carry out the comprehensive optimization of piercing efficiency and energy consumption and take the following formula as the optimization model to seek the optimum decision variable value of $\bar{x}_{1}, \bar{x}_{2}, \ldots, \bar{x}_{17}$ :

$$
\max y=k_{1} f(\mathbf{x}, \boldsymbol{\theta})+\frac{k_{2}}{f\left(\mathbf{x}^{\prime}, \boldsymbol{\theta}^{\prime}\right)},
$$

where $f(\mathbf{x}, \boldsymbol{\theta})$ and $f\left(\mathbf{x}^{\prime}, \boldsymbol{\theta}^{\prime}\right)$ are piercing efficiency and energy consumption, respectively, which are calculated by mean value substaged KELM-PLS method; $k_{1}$ and $k_{2}$ are the weighted values of adjustment of optimization objective, the adjustment range of $k_{1}$ is $0 \sim 13$, and the adjustment range of $k_{2}$ is $0 \sim 11$. When the rate of capacity utilization is lower, it is necessary to maximize $k_{2}$, and in this way the energy consumption in production can be reduced and at the same time the production cost can be reduced, thus maximizing the production benefit. Similarly, when the rate of capacity utilization is higher and the supply and marketing of product are flourishing, it is necessary to maximize $k_{1}$, in order to guarantee that the production line of seamless tube operates in the state of maximum efficiency, and in this way, the maximum benefit of production can also be obtained. In other conditions, it is necessary to carry out the adjustment according to the experience and concrete conditions. follows:

The constraint condition of production optimization is as

(1) the change range of production process parameters of piercing equipment

$$
\begin{array}{ll}
\text { s.t.1 } & 105 \leq \bar{x}_{1}, \bar{x}_{8}, \bar{x}_{13} \leq 195, \\
& 0 \leq \bar{x}_{4} \leq 2550, \\
& 115 \leq \bar{x}_{5} \leq 170, \\
& 1200 \leq \bar{x}_{7} \leq 1300, \\
& 200 \leq \bar{x}_{6}, \bar{x}_{11}, \bar{x}_{16} \leq 300, \\
& 120 \leq \bar{x}_{2}, \bar{x}_{9}, \bar{x}_{14} \leq 170, \\
& 10 \leq \bar{x}_{3}, \bar{x}_{10}, \bar{x}_{15} \leq 14, \\
& 20 \leq \bar{x}_{12}, \bar{x}_{17} \leq 30 ;
\end{array}
$$


TABLE 2: Decision making variable table of optimization.

\begin{tabular}{|c|c|c|c|c|}
\hline Number & Variables & $\begin{array}{c}\text { Decision variables } \\
\text { of piercing } \\
\text { efficiency }\end{array}$ & $\begin{array}{c}\text { Decision variables of } \\
\text { piercing energy } \\
\text { consumption }\end{array}$ & The mean of variables \\
\hline 1 & $\bar{x}_{1}$ & $\sqrt{ }$ & $\sqrt{ }$ & The rotational speed of roll at first stage \\
\hline 2 & $\bar{x}_{2}$ & $\sqrt{ }$ & $\sqrt{ }$ & The percent reduction of roll at first stage \\
\hline 3 & $\bar{x}_{3}$ & $\sqrt{ }$ & $\sqrt{ }$ & The angle of inclination of roll at first stage \\
\hline 4 & $\bar{x}_{4}$ & $\sqrt{ }$ & & The position change range of pusher \\
\hline 5 & $\bar{x}_{5}$ & $\sqrt{ }$ & & The actual position of mandrel thrust block \\
\hline 6 & $\bar{x}_{6}$ & $\sqrt{ }$ & & The position of mandrel at first stage \\
\hline 7 & $\bar{x}_{7}$ & $\sqrt{ }$ & $\sqrt{ }$ & The temperature of tube blank at second stage \\
\hline 8 & $\bar{x}_{8}$ & $\sqrt{ }$ & $\sqrt{ }$ & The rotational speed of roll at second stage \\
\hline 9 & $\bar{x}_{9}$ & $\sqrt{ }$ & $\sqrt{ }$ & The percent reduction of roll at second stage \\
\hline 10 & $\bar{x}_{10}$ & $\sqrt{ }$ & $\sqrt{ }$ & The angle of inclination of roll at second stage \\
\hline 11 & $\bar{x}_{11}$ & $\sqrt{ }$ & & The position of mandrel at second stage \\
\hline 12 & $\bar{x}_{12}$ & $\sqrt{ }$ & $\sqrt{ }$ & The rotational speed of guide disc at second stage \\
\hline 13 & $\bar{x}_{13}$ & $\sqrt{ }$ & $\sqrt{ }$ & The rotational speed of roll at third stage \\
\hline 14 & $\bar{x}_{14}$ & $\sqrt{ }$ & $\sqrt{ }$ & The percent reduction of roll at third stage \\
\hline 15 & $\bar{x}_{15}$ & $\sqrt{ }$ & $\sqrt{ }$ & The angle of inclination of roll at third stage \\
\hline 16 & $\bar{x}_{16}$ & $\sqrt{ }$ & & The position of mandrel at third stage \\
\hline 17 & $\bar{x}_{17}$ & $\sqrt{ }$ & $\sqrt{ }$ & The rotational speed of guide disc at third stage \\
\hline
\end{tabular}

TABLE 3: Comparison of the production index after optimization of piercing efficiency and energy consumption.

\begin{tabular}{|c|c|c|c|c|}
\hline \multirow{2}{*}{ Method of modeling } & \multicolumn{2}{|c|}{ Piercing efficiency } & \multicolumn{2}{|c|}{ Piercing energy consumption } \\
\hline & Accuracy of model & Time of modeling & Accuracy of model & Time of modeling \\
\hline Mean value substaged KELM-PLS & 92.14 & 0.39 & 93.14 & 0.32 \\
\hline MICR & 91.12 & 0.36 & 90.53 & 0.30 \\
\hline MPLS & 90.21 & 0.52 & 89.56 & 0.48 \\
\hline
\end{tabular}

TABLE 4: Optimization result of piercing efficiency and energy consumption.

\begin{tabular}{|c|c|c|c|c|c|}
\hline Number & $\begin{array}{l}\text { Decision } \\
\text { variables }\end{array}$ & The mean of variables & $\begin{array}{l}\text { Optimization results in the } \\
\text { highest efficiency piercing }\end{array}$ & $\begin{array}{l}\text { Optimization results in the } \\
\text { lowest energy consumption }\end{array}$ & Unit \\
\hline 1 & $\bar{x}_{1}$ & The rotational speed of roll at first stage & 136.72 & 120.91 & $\mathrm{r} / \mathrm{min}$ \\
\hline 2 & $\bar{x}_{2}$ & The percent reduction of roll at first stage & 144.75 & 140.13 & $\mathrm{~mm}$ \\
\hline 3 & $\bar{x}_{3}$ & The angle of inclination of roll at first stage & 13.71 & 12.33 & $\circ$ \\
\hline 4 & $\bar{x}_{4}$ & The position change range of pusher & 2549.63 & 2547.32 & $\mathrm{~mm}$ \\
\hline 5 & $\bar{x}_{5}$ & The actual position of mandrel thrust block & 115.64 & 112.42 & $\mathrm{~mm}$ \\
\hline 6 & $\bar{x}_{6}$ & The position of mandrel at first stage & 279.32 & 279.43 & $\mathrm{~mm}$ \\
\hline 7 & $\bar{x}_{7}$ & The temperature of tube blank at second stage & 1286.23 & 1251.54 & ${ }^{\circ} \mathrm{C}$ \\
\hline 8 & $\bar{x}_{8}$ & The rotational speed of roll at second stage & 171.82 & 154.43 & $\circ$ \\
\hline 9 & $\bar{x}_{9}$ & The percent reduction of roll at second stage & 144.86 & 142.75 & $\mathrm{~mm}$ \\
\hline 10 & $\bar{x}_{10}$ & The angle of inclination of roll at second stage & 13.47 & 12.49 & $\circ$ \\
\hline 11 & $\bar{x}_{11}$ & The position of mandrel at second stage & 280.56 & 277.78 & $\mathrm{~mm}$ \\
\hline 12 & $\bar{x}_{12}$ & The rotational speed of guide disc at second stage & 26.74 & 26.15 & $\mathrm{r} / \mathrm{min}$ \\
\hline 13 & $\bar{x}_{13}$ & The rotational speed of roll at third stage & 152.51 & 137.69 & $\mathrm{r} / \mathrm{min}$ \\
\hline 14 & $\bar{x}_{14}$ & The percent reduction of roll at third stage & 146.43 & 142.74 & $\mathrm{~mm}$ \\
\hline 15 & $\bar{x}_{15}$ & The angle of inclination of roll at third stage & 13.73 & 12.34 & $\circ$ \\
\hline 16 & $\bar{x}_{16}$ & The position of mandrel at third stage & 280.64 & 278.87 & $\mathrm{~mm}$ \\
\hline 17 & $\bar{x}_{17}$ & The rotational speed of guide disc at third stage & 28.65 & 26.78 & $\mathrm{r} / \mathrm{min}$ \\
\hline
\end{tabular}


(2) the bite condition of seamless tube piercing production

$$
\text { s.t.2 } 2 T_{i}>Q_{i}+2 P_{i} \text {. }
$$

Among them, $i$ is the number of substage of piercings, $i=$ $1,2,3 ; T_{i}$ is the axial dragged-into frictional force $T_{i}=$ $p_{i} f b_{i} L_{H i} \cos \theta_{i}$ of one roll to affect the tube blank, $N$; $P_{i}$ is the positive pressure axial component $P_{i}=p_{i} b_{i} L_{H i} \sin \theta_{i}$ of one roll to affect the tube blank, $N$; and $Q_{i}$ is the resistance of piercing head, $N$.

Consider

$$
\begin{aligned}
Q_{i}= & p_{i} \pi r_{H}^{2} \\
& \times\left(\frac{2 \pi n_{i}}{60} \frac{D_{G}}{d_{G J}} \sin \theta_{i}+\frac{1+\left(d_{K J} / d_{G J}\right)^{2}}{1+d_{K J} / d_{G J}}\right)\left(\frac{2 \pi n_{i}}{60}\right)^{-1} .
\end{aligned}
$$

In the formula, $p_{i}$ is the mean specific roll pressure, $\mathrm{Kg} / \mathrm{mm}^{2} ; f$ is the friction coefficient; $\theta_{i}$ is the angle of inclination of roll, rad; $n_{i}$ is the rotational speed of roll, $\mathrm{rad} / \mathrm{min} ; r_{H}$ is the radius of nose of piercing head, $\mathrm{mm} ; L_{H i}$ is the length of deformed zone, $\mathrm{mm} ; b_{i}$ is the percent reduction of roll, $\mathrm{mm} ; D_{G}$ is the diameter of roll waist, $\mathrm{mm} ; d_{G J}$ is the distance of roll at the place of inlet, $\mathrm{mm}$; and $d_{K J}$ is the distance of roll at the place of bore throat, $\mathrm{mm}$.

In the constrained conditions shown in formula (17), the rotational speed of rolls $n_{1}, n_{2}, n_{3}$ corresponds to the decision variables $\bar{x}_{1}, \bar{x}_{8}, \bar{x}_{13}$, respectively; the percent reduction of roll $b_{1}, b_{2}, b_{3}$ corresponds to the decision variables $\bar{x}_{2}, \bar{x}_{9}, \bar{x}_{14}$, respectively; the angle of inclination of rolls $\theta_{1}, \theta_{2}, \theta_{3}$ corresponds to the decision variables $\bar{x}_{3}, \bar{x}_{10}, \bar{x}_{15}$, respectively; and the position of mandrels $L_{H_{1}}, L_{H_{2}}, L_{H_{3}}$ corresponds to the decision variables $\bar{x}_{6}, \bar{x}_{11}, \bar{x}_{16}$, respectively.

(3) The quality of shell produced by the cross piercing should meet the requirements of site

$$
\text { s.t.3 } M_{P}=f_{\text {quality }}(x)<M_{N} \text {. }
$$

In the formula, $M_{N}=$ the requirements for quality, $\% ; M_{P}$ $=$ the quality of shell, $\%$; and $f_{\text {quality }}()=$ the quality of shell calculated by the quality prediction model [32].

Finally, by formula (17) formula (22), the model of comprehensive optimization of piercing efficiency and energy consumption can be expressed as follows:

$$
\begin{array}{ll}
\max & y=k_{1} \mathbf{x} \boldsymbol{\theta}+k_{2} \mathbf{x}^{\prime} \boldsymbol{\theta}^{\prime} \\
\text { s.t. } & 105 \leq \bar{x}_{1}, \bar{x}_{8}, \bar{x}_{13} \leq 195, \\
& 0 \leq \bar{x}_{4} \leq 2550, \\
& 115 \leq \bar{x}_{5} \leq 170, \\
& 1200 \leq \bar{x}_{7} \leq 1300, \\
& 200 \leq \bar{x}_{6}, \bar{x}_{11}, \bar{x}_{16} \leq 300,
\end{array}
$$

$$
\begin{aligned}
& 120 \leq \bar{x}_{2}, \bar{x}_{9}, \bar{x}_{14} \leq 170, \\
& 10 \leq \bar{x}_{3}, \bar{x}_{10}, \bar{x}_{15} \leq 14, \\
& 20 \leq \bar{x}_{12}, \bar{x}_{17} \leq 30, \\
& 2 T_{i}>Q_{i}+2 P_{i}, \\
& M_{P}=f_{\text {quality }}(x)<M_{N} .
\end{aligned}
$$

5.2. Comprehensive Optimization of Piercing Efficiency and Energy Consumption. The comprehensive optimization of piercing efficiency and energy consumption is an optimization issue with constraint condition, and this paper selects the genetic algorithm as the algorithm to find the solution of model of comprehensive optimization of piercing efficiency and energy consumption. Flow chart of piercing efficiency and energy optimization is shown in Figure 4.

(1) The definition of the fitness function of piercing efficiency and energy consumption optimization is as follows:

$$
\max y=k_{1} f(\mathbf{x}, \boldsymbol{\theta})+\frac{k_{2}}{f\left(\mathbf{x}^{\prime}, \boldsymbol{\theta}^{\prime}\right)} .
$$

In the formula, $\boldsymbol{\theta}$ is the coefficient of model of piercing efficiency; $\boldsymbol{\theta}^{\prime}$ is the coefficient of model of piercing energy consumption; $\mathbf{x}$ is the decision variable of optimization of piercing efficiency; and $\mathbf{x}^{\prime}$ is the decision variable of optimization of piercing energy consumption. $f()$ is the model output of mean value substaged KELM-PLS method.

(2) Because the comprehensive optimization of piercing efficiency and energy consumption is an issue of continuous parameters optimization, float encoding is adopted as the encoding mode. It avoids the length limitation of binary encoding which reduces the performance and solution accuracy. Float encoding does not require coding and decoding operation which improves the computing speed and accuracy to solve. At the same time, the integral arithmetic crossover algorithm is adopted [33, 34].

(3) Punishment technology is commonly used for constrained optimization problems in genetic algorithm. Penalty function methods transform a constrained optimization problem into a sequence of unconstrained optimization problems. The constraints are appended to the objective function via a penalty parameter and a penalty function. In general, a feasible penalty function should admit a positive penalty for infeasible points and no penalty for feasible points. The fitness function is designed for

$$
\begin{aligned}
F= & y-m_{1} \times \max \left\{0, g_{1}(x)\right\}-m_{2} \times \max \left\{0, g_{2}(x)\right\} \\
& -m_{3} \times \max \left\{0, g_{3}(x)\right\}-m_{4} h(x),
\end{aligned}
$$

where $g_{1}$ is the inequality constraint of formula (18), $g_{2}$ is the inequality constraint of formula (19), $g_{3}$ is the inequality constraint of formula (21), and $h$ is the equality constraint of formula (20).

(4) GA algorithm stopping convergence condition is as follows. When the algorithm is run continuously for 20 generations, it stops if the fitness value changes to less than $10^{-6}$. And it stops when the algorithm is run continuously for 1000 generations. 


\section{Simulation and Experiment}

In order to verify the accuracy of the method, this paper selects the data of production of 90 piercing tubes of Diescher Mannesmann piercer of seamless tube factory of Baosteel company in January 2014. The first 65 shells are used to build the prediction model of piercing efficiency and energy consumption and the last 25 shells are used for the inspection of accuracy of model. The test process conditions are as follows: the diameter of roll: $D_{g}=1000 \mathrm{~mm}$, the cone angle of inlet: $\beta=2.75^{\circ}$, the diameter of guide disc: $D_{p}=1800 \mathrm{~mm}$, the toe angle: $\Phi=0^{\circ}$, the distance of guide disc: $L_{p}=$ $173 \mathrm{~mm}$, the rotational speed of guide disc: 26 revolutions per minute, the initial temperature of guide disc: $100^{\circ} \mathrm{C}$, the rotational speed of roll: 185 revolutions per minute, the initial temperature of roll: $150^{\circ} \mathrm{C}$, the percent reduction of roll: $150 \mathrm{~mm}$, the change range of angle of inclination of roll: $13^{\circ}$, the temperature of piercing head: $100^{\circ} \mathrm{C}$, the temperature of tube blank: $1250^{\circ} \mathrm{C}$, the specification of tube blank: $\Phi 178 \mathrm{~mm}$, the specification of shell: $\Phi 179 \mathrm{~mm} \times 30.25 \mathrm{~mm}$, and the quality of material: C22 (20\# steel).

First, the production data of 90 shells are handled to obtain the input data $\mathbf{X}(65,28)$ and $\mathbf{X}^{\prime}(65,23)$ for modeling of piercing efficiency and energy consumption as well as the input data $\mathbf{X}_{\text {new }}(25,28)$ and $\mathbf{X}_{\text {new }}^{\prime}(25,23)$ for inspection of piercing efficiency and energy consumption according to Figure 2 and Table 1 . After using the mean value substaged KELM-PLS method to build the prediction models of piercing efficiency and energy consumption, respectively, the input data $\mathbf{X}_{\text {new }}(25,28)$ and $\mathbf{X}_{\text {new }}^{\prime}(25,23)$ for inspection of piercing efficiency and energy consumption are put into formula (5), respectively, and their precision of model is compared with the precision of the model of actual values $\mathbf{y}(25,1)$ and $\widehat{\mathbf{y}}^{\prime}(25,1)$. And at the same time, the prediction model of efficiency and piercing energy consumption of traditional MPLS method is built. The following 12 process variables that affect the piercing efficiency are selected: the intermesh of upper roll and lower roll, the values of angles of inclination of upper and lower rolls, the rotational speed of upper roll and lower roll, the position of pusher, the actual position of mandrel thrust block, the position of mandrel, the rotational speed of left and right discs, and the temperature of tube blank. Similarly, the production data of 25 shells are utilized to carry out the inspection of model. Figures 5 and 6 show the results of comparison among the inspections of the models of piercing efficiency and the piercing energy consumption of three kinds of methods which are mean value substaged KELM-PLS, MICR [7], and MPLS method.

As shown in Figures 5 and 6, the prediction accuracies of model of piercing efficiency on the basis of mean value substaged KELM-PLS, MICR, and MPLS model are 92.14\%, 91.12 , and $90.21 \%$, respectively, and the input variables of their models are 28 and 1101 variables, respectively. The calculation times used by the models are 0.39 seconds, 0.36 seconds, and 0.52 seconds. The prediction accuracies of model of piercing energy consumption on the basis of mean value substaged KELM-PLS, MICR, and MPLS model are 93.14\%, 90.53\%, and

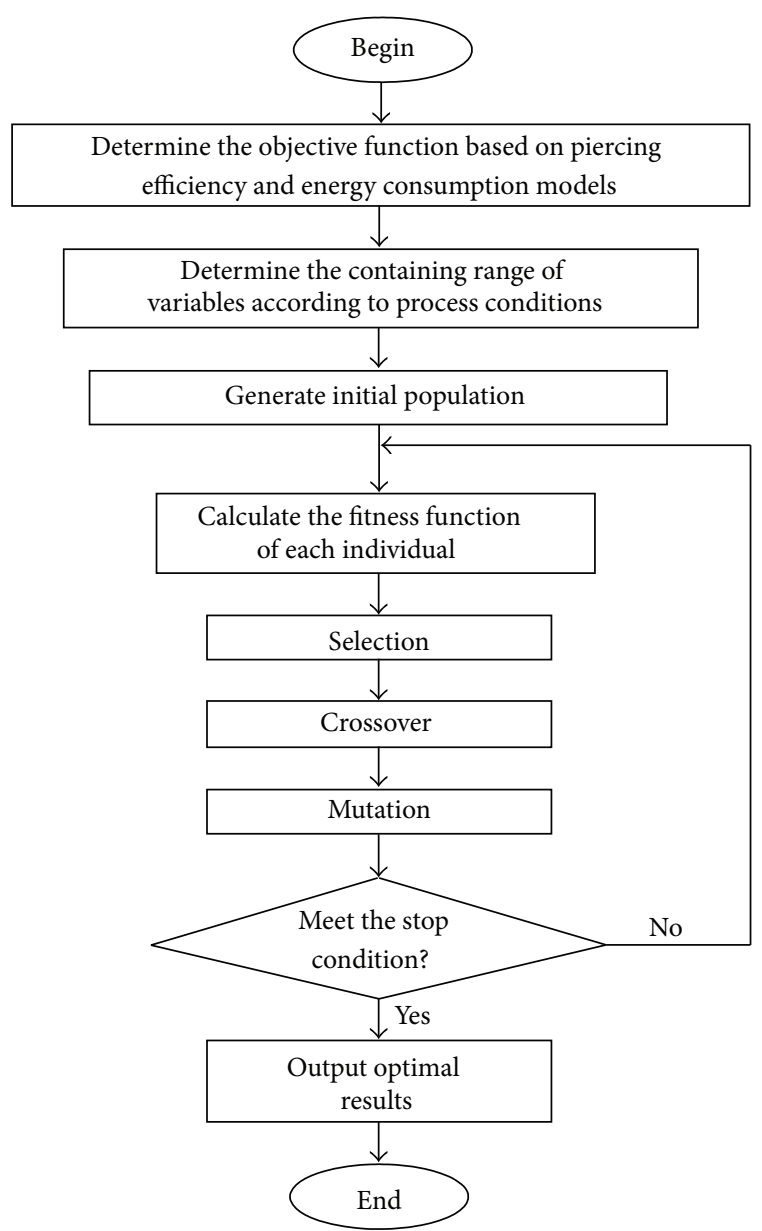

FIgURE 4: Flow chart of optimization.

$89.56 \%$, respectively, and the input variables of their models are 23 and 801 variables, respectively. The calculation times of models are 0.32 seconds, 0.30 seconds, and 0.48 seconds, respectively. Table 3 indicates the comparison among the three kinds of methods of piercing efficiency and energy consumption. It can be found from this condition that the model of mean value substaged KELM-PLS method increases the prediction accuracy of model to a certain extent, and at the same time, the reduction of input quantity of model also greatly reduces the calculation time used by the model, which makes the model more easy to use online. Figure 7 shows that maximum piercing efficiency is taken as the strategy of seeking optimization when the influence of the piercing energy consumption is not considered. The maximum piercing efficiency obtained by the optimization is $90.24 \%$. Figure 8 shows that the minimum energy piercing consumption is taken as the strategy of seeking optimization when the piercing efficiency is not considered. The minimum piercing energy consumption obtained by the optimization is $8.268 \mathrm{Kwh}$. And at the same time, the production process parameter values in every stage that minimize the piercing energy consumption are found out. Table 4 indicates the parameter values of production process in every stage and Table 5 indicates the comparison between the indexes of 
TABLE 5: Comparison of the production index after optimization of piercing efficiency and energy consumption.

\begin{tabular}{|c|c|c|c|c|}
\hline Production index of piercing & Before optimization & $\begin{array}{l}\text { After optimization } \\
\text { with MICR model }\end{array}$ & $\begin{array}{l}\text { After optimization with } \\
\text { KELM-PLS model }\end{array}$ & Unit \\
\hline Piercing efficiency & 84.56 & 88.93 & 90.24 & $\%$ \\
\hline Piercing energy consumption & 11.352 & 8.341 & 8.268 & KWh \\
\hline
\end{tabular}

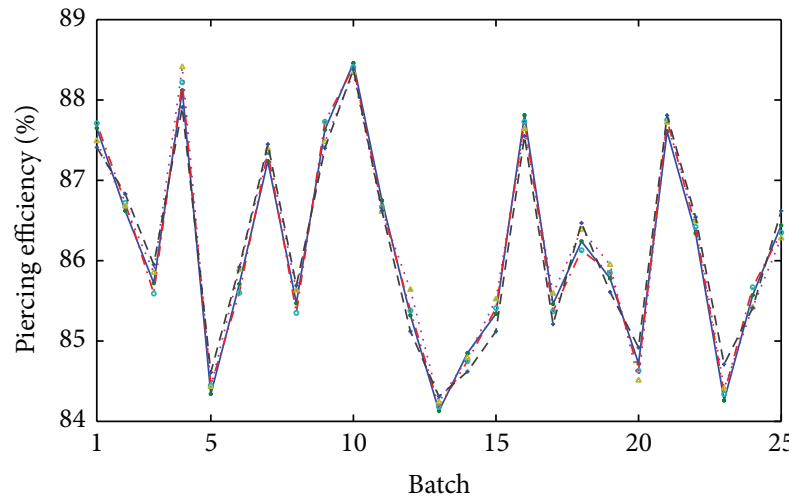

-. Measure values $\quad$....... MICR predicted values - - - KELM-PLS predicted values -+- MPLS predicted values

Figure 5: Test result of piercing efficiency model.

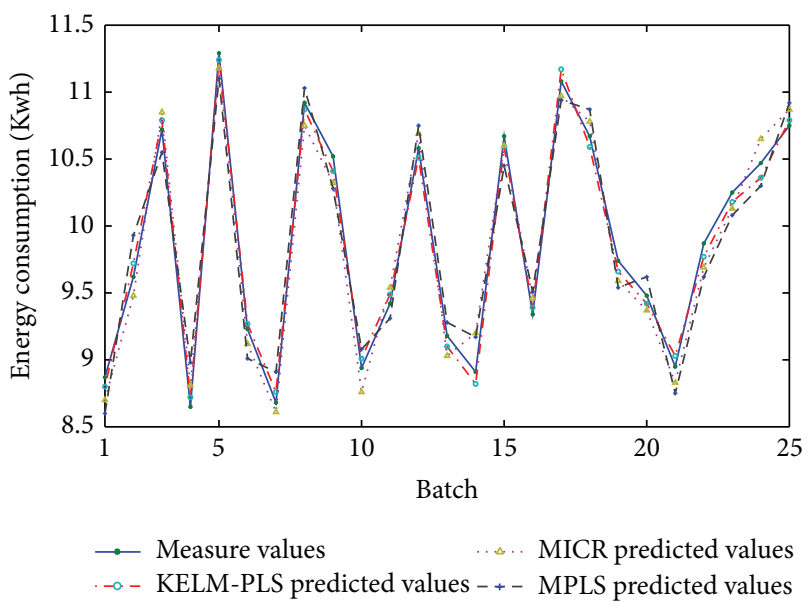

FIGURE 6: Test result of piercing energy consumption model.

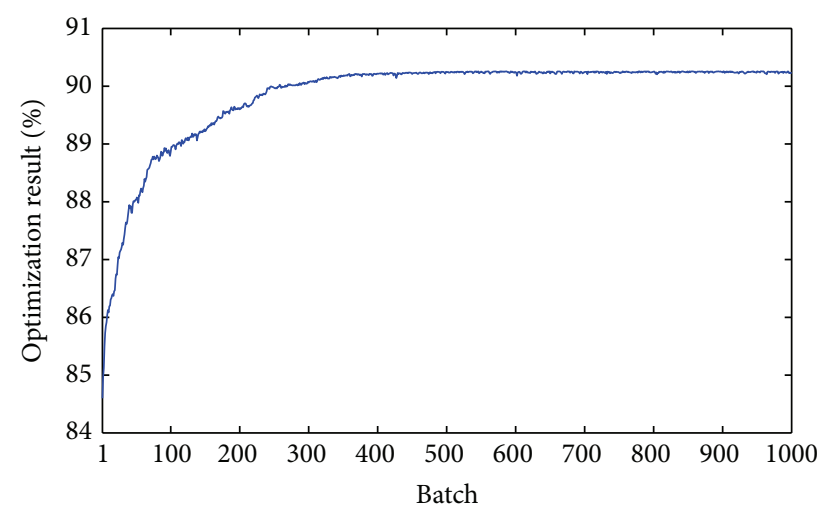

FIGURE 7: Optimization result with maximum piercing efficiency.

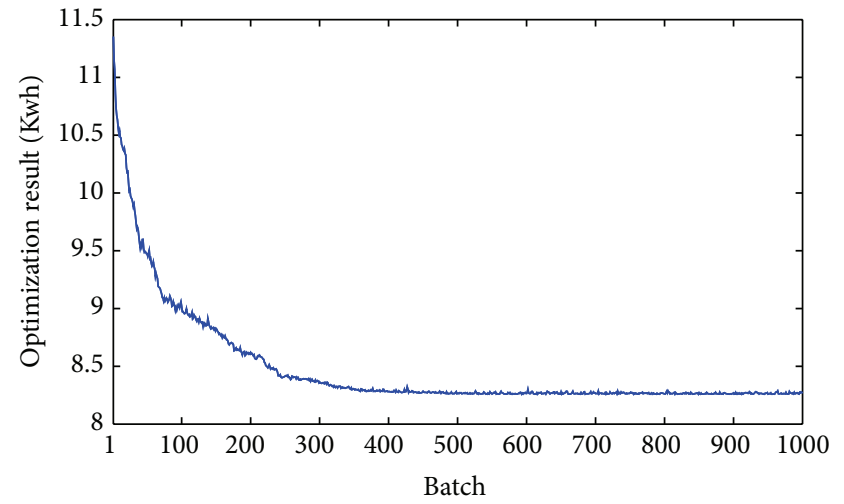

FIgURE 8: Optimization result with minimum piercing energy consumption.

piercing efficiency and energy consumption before and after the optimization.

\section{Conclusions}

For the process of producing the shell of seamless tube by piercing, this paper adopts the mean value substaged KELM-PLS modeling method, builds the prediction model of piercing efficiency and energy consumption, and provides the online prediction of piercing efficiency and energy consumption of tube blank. On this basis, the genetic algorithm is adopted for the comprehensive optimization of piercing efficiency and energy consumption and the optimum production process parameters are obtained according to the different market demands and constraint conditions. The test indicates that when the minimum energy consumption is required, the optimized energy consumption of production is reduced obviously, and at the same time, the cost of production is reduced, and when the high production efficiency is required, the optimized production increases the piercing efficiency to a certain extent, which can guarantee that the production task is finished smoothly. Meanwhile, the method can also be spread to the application to the index predication and optimization of other multistage batch processes.

\section{Conflict of Interests}

The authors declare that there is no conflict of interests regarding the publication of this paper. 


\section{Acknowledgments}

This research is supported by National Natural Science Foundation of China (Grant nos. 61203214), National Natural Science Foundation of China (Grant nos. 61203103, 61374146, 61374147) and Provincial Science and Technology Department of Education Projects (L2013101).

\section{References}

[1] M. A. Cavaliere, M. B. Goldschmit, and E. N. Dvorkin, "Finite element analysis of steel rolling processes," Computers and Structures, vol. 79, no. 22-25, pp. 2075-2089, 2001.

[2] L.-S. Li, Steel Tube Plastic Deformation Theory, Metallurgical Industry Press, Beijing, China, 1985, (Chinese).

[3] Y.-H. Shuang, Numerical Simulation Theory and Cross Rolling Steel Production Process, Metallurgical Industry Press, Beijing, China, 2001, (Chinese).

[4] X.-Y. Yang and Y. Liu, "Establishment of math model for piercing efficiency," Steel Tube, vol. 24, no. 5, pp. 30-33, 1995 (Chinese).

[5] Y.-H. Pang, Z.-M. Zhou, and Y.-Y. Cheng, "Influence of plug configuration on wall-thickness uniformity and energy consumption during shell piercing," Steel Tube, vol. 20, no. 5, pp. 48-53, 1991 (Chinese).

[6] D. Xiao, X.-L. Pan, Y. Yuan, Z.-Z. Mao, and F.-L. Wang, "Modeling and optimization for piercing energy consumption," Journal of Iron and Steel Research International, vol. 16, no. 2, pp. 40-44, 2009.

[7] D. Xiao, J.-C. Wang, X.-L. Pan, and Z.-Z. Mao, "Modeling and optimization for piercing efficiency and energy consumption," Journal of Iron and Steel Research, vol. 25, no. 1, pp. 14-22, 2013 (Chinese).

[8] W. Kitagawa, Y. Kimura, and T. Takeshita, "A study on embedding genetic algorithm to three-dimensional finite element method by using shell script," IEEJ Transactions on Industry Applications, vol. 132, no. 2, pp. 227-232, 2012.

[9] D.-L. Liu, X.-H. Chen, and J.-L. Du, "A hybrid genetic algorithm for constrained optimization problems," Journal of Computers, vol. 8, no. 2, pp. 272-278, 2013.

[10] S.-F. Ding, L. Xu, C.-Y. Su, and F.-X. Jin, "An optimizing method of RBF neural network based on genetic algorithm," Neural Computing and Applications, vol. 21, no. 2, pp. 333-336, 2012.

[11] S. Wold, N. Kettaneh-Wold, and B. Skagerberg, "Nonlinear PLS modeling," Chemometrics and Intelligent Laboratory Systems, vol. 7, no. 1-2, pp. 53-65, 1989.

[12] S. J. Qin, "Recursive PLS algorithms for adaptive data modeling," Computers \& Chemical Engineering, vol. 22, no. 4-5, pp. 503-514, 1998.

[13] B. Hu, Z. Zhao, and J. Liang, "Multi-loop nonlinear internal model controller design under nonlinear dynamic PLS framework using ARX-neural network model," Journal of Process Control, vol. 22, no. 1, pp. 207-217, 2012.

[14] A. Bueno-Crespo, P. J. García-Laencina, and J.-L. SanchoGómez, "Neural architecture design based on extreme learning machine," Neural Networks, vol. 48, pp. 19-24, 2013.

[15] W. Xi-Zhao, S. Qing-Yan, M. Qing, and Z. Jun-Hai, "Architecture selection for networks trained with extreme learning machine using localized generalization error model," Neurocomputing, vol. 102, pp. 3-9, 2013.
[16] J. Zhai, H. Xu, and Y. Li, "Fusion of extreme learning machine with fuzzy integral," International Journal of Uncertainty, Fuzziness and Knowledge-Based Systems, vol. 21, supplement 2, pp. 23-34, 2013.

[17] G.-B. Huang, "An insight into extreme learning machines: random neurons, random features and kernels," Cognitive Computation, 2014.

[18] G. Huang, S. Song, J. N. D. Gupta, and C. Wu, "Semisupervised and unsupervised extreme learning machines," IEEE Transactions on Cybernetics, 2014.

[19] J. W. Cao, T. Chen, and J. Fan, "Fast online learning algorithm for landmark recognition based on BoW framework," in Proceedings of the 9th IEEE Conference on Industrial Electronics and Applications, June 2014.

[20] Y. Jin, J. W. Cao, Q. Q. Ruan, and X.-Q. Wang, "Cross-modality 2D-3D face recognition via multiview smooth discriminant analysis based on ELM," Journal of Electrical and Computer Engineering, vol. 2014, Article ID 584241, 9 pages, 2014.

[21] G.-B. Huang, D.-H. Wang, and Y. Lan, "Extreme learning machines: a survey," International Journal of Machine Learning and Cybernetics, vol. 2, no. 2, pp. 107-122, 2011.

[22] G. Feng, Z. Qian, and N. Dai, "Reversible watermarking via extreme learning machine prediction," Neurocomputing, vol. 82, pp. 62-68, 2012.

[23] Y. Yu, T.-M. Choi, and C.-L. Hui, "An intelligent quick prediction algorithm with applications in industrial control and loading problems," IEEE Transactions on Automation Science and Engineering, vol. 9, no. 2, pp. 276-287, 2012.

[24] Y.-M. Yang, Y.-N. Wang, and X.-F. Yuan, "Bidirectional extreme learning machine for regression problem and its learning effectiveness," IEEE Transactions on Neural Networks and Learning Systems, vol. 23, no. 9, pp. 1498-1505, 2012.

[25] J. W. Cao and L. Xiong, "Protein sequence classification with improved extreme learning machine algorithms," BioMed Research International, vol. 2014, Article ID 103054, 12 pages, 2014.

[26] L.-L. Kasun, H. Zhou, G.-B. Huang, and C.-M. Vong, "Representational learning with extreme learning machine for big data," IEEE Intelligent Systems, vol. 28, no. 6, pp. 31-34, 2013.

[27] G.-B. Huang, H.-M. Zhou, X.-J. Ding, and R. Zhang, "Extreme learning machine for regression and multiclass classification," IEEE Transactions on Systems, Man, and Cybernetics, B: Cybernetics, vol. 42, no. 2, pp. 513-529, 2012.

[28] J. Kamran, G. Rafael, and Z. Noureddine, "SW-ELM: a summation wavelet extreme learning machine algorithm with a priori parameter initialization," Neurocomputing, vol.123, pp. 299-307, 2014.

[29] J.-H. Zhai, H.-Y. Xu, and X.-Z. Wang, "Dynamic ensemble extreme learning machine based on sample entropy," Soft Computing, vol. 16, no. 9, pp. 1493-1502, 2012.

[30] W. He, E. -J. Wang, and T. Xiong, "Intelligent face recognition based on manifold learning and genetic-chaos algorithm optimized Kernel extreme learning machine," Journal of Communications, vol. 8, no. 10, pp. 658-664, 2013.

[31] G. B. Huang, H. M. Zhou, X.-J. Ding, and R. Zhang, "Extreme learning machines for regression and muticlass classification," IEEE Transaction on Systems Man and Cybernetics B, vol. 42, no. 2, pp. 513-529, 2011.

[32] X. Dong, P. Xiaoli, and M. Zhizhong, "Quality prediction of tube hollow based on step-by-step staged MICR," Chinese Journal of Scientific Instrument, vol. 28, no. 12, pp. 2190-2196, 2007 (Chinese). 
[33] C. Wang and Y.-H. Gao, "Determination of power distribution network configuration using non-revisiting genetic algorithm," IEEE Transactions on Power Systems, vol. 28, no. 4, pp. 36383648, 2013.

[34] M. Murali, M. S. Kumari, and M. Sydulu, "Estimation of locational marginal price in a restructured electricity market with different loss cases using seed genetic algorithm," Arabian Journal for Science and Engineering, vol. 39, no. 2, pp. 1089-1106, 2014. 


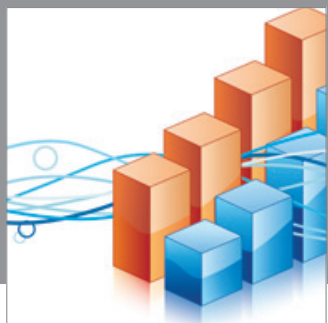

Advances in

Operations Research

mansans

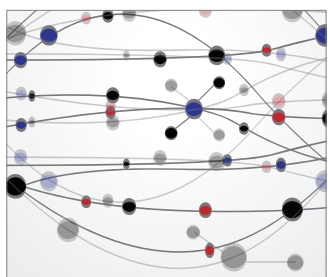

The Scientific World Journal
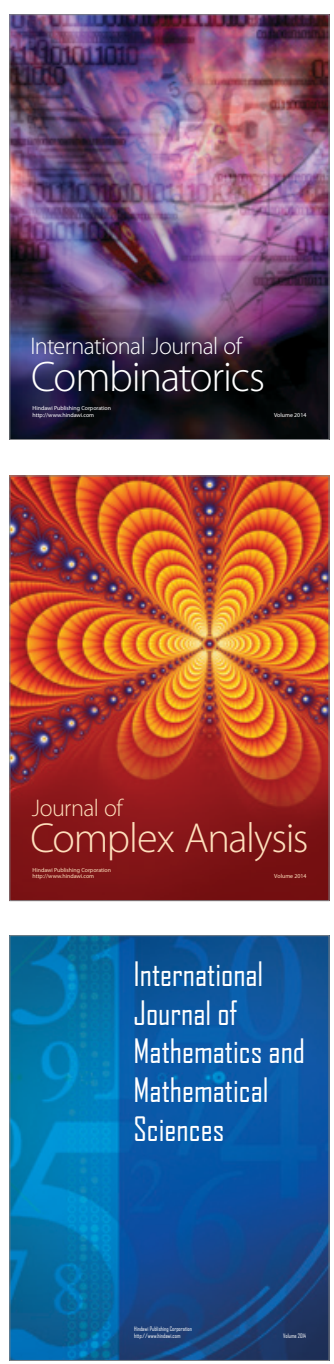
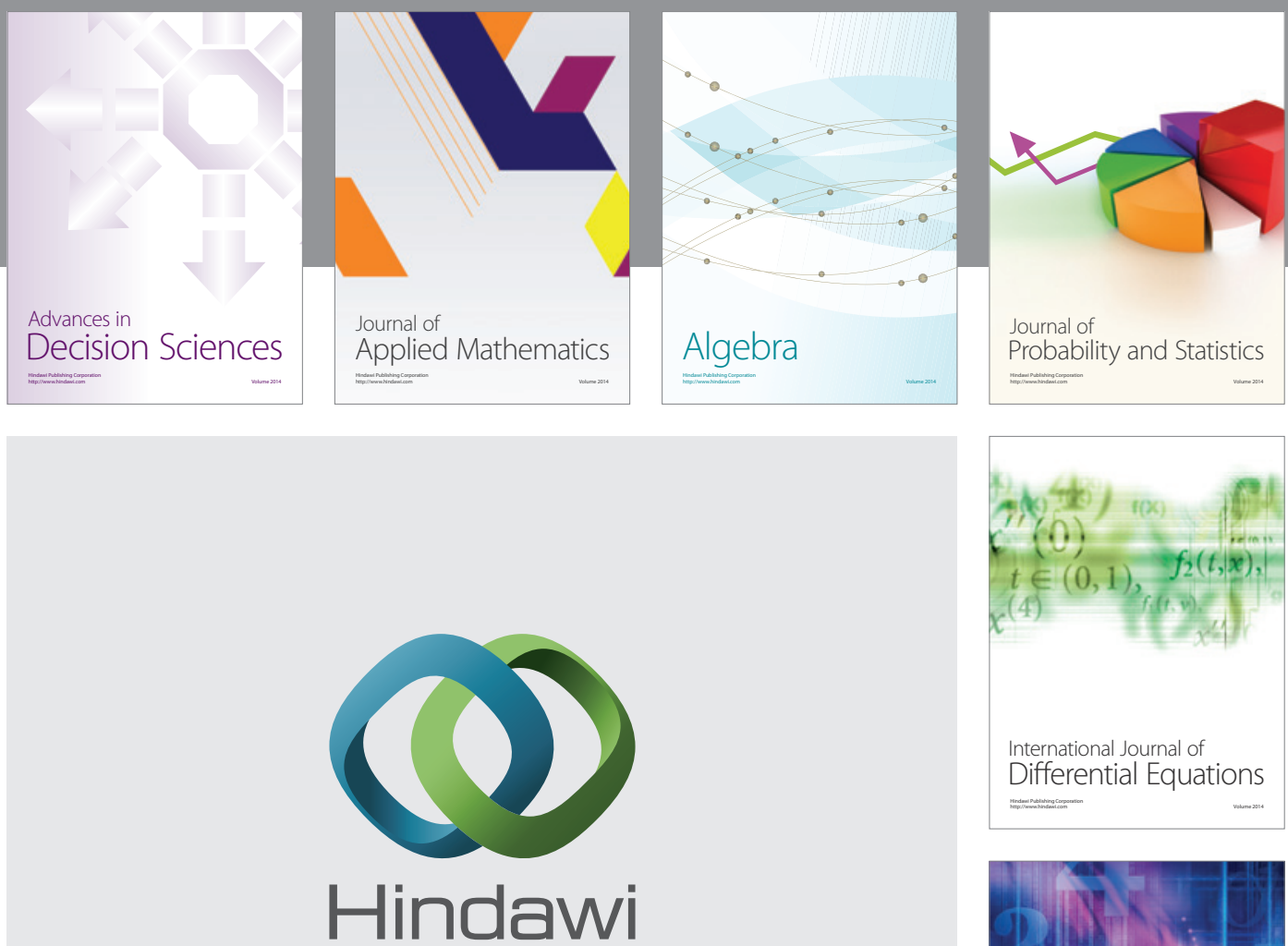

Submit your manuscripts at http://www.hindawi.com
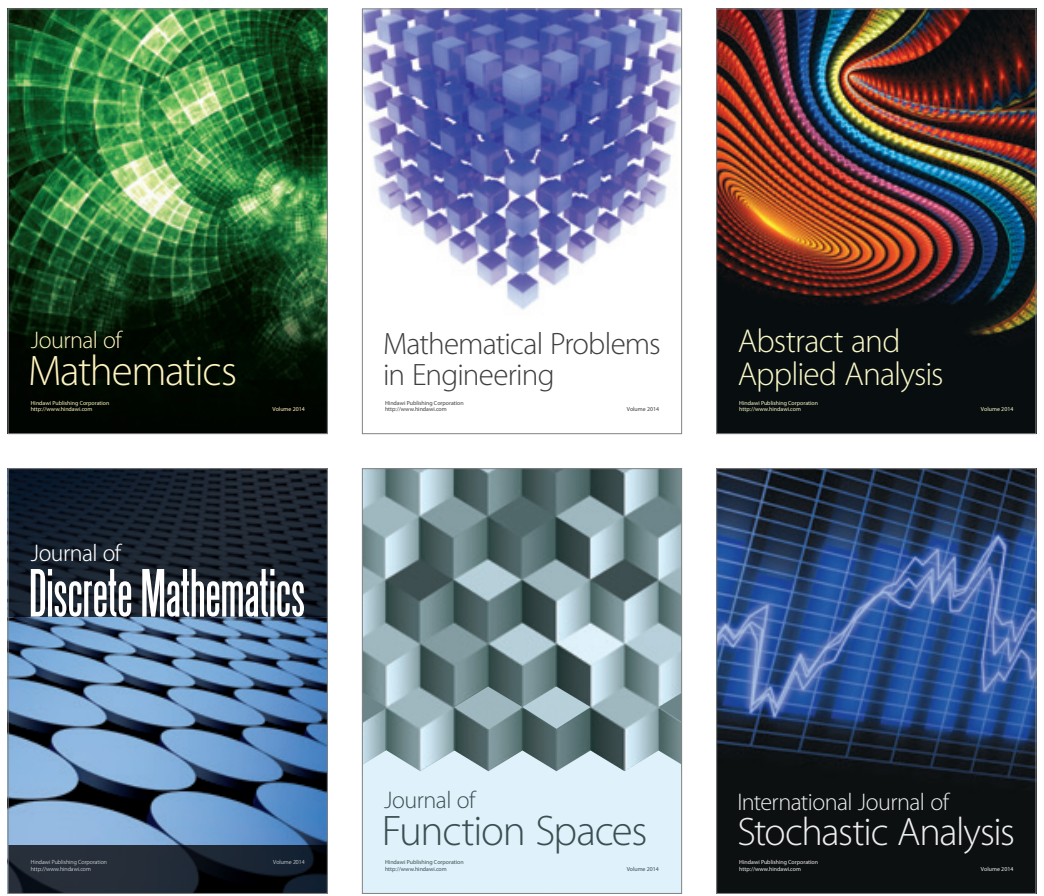

Journal of

Function Spaces

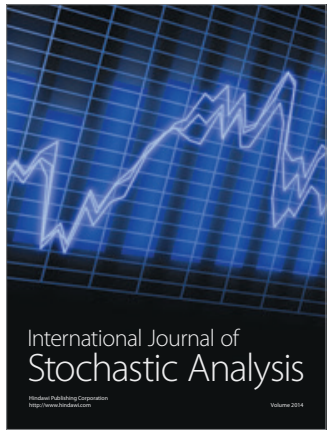

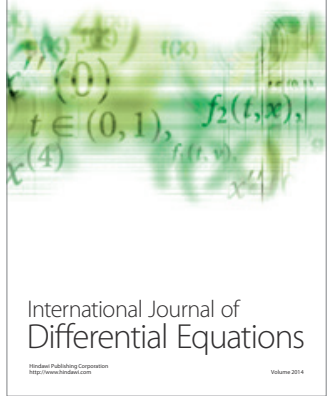
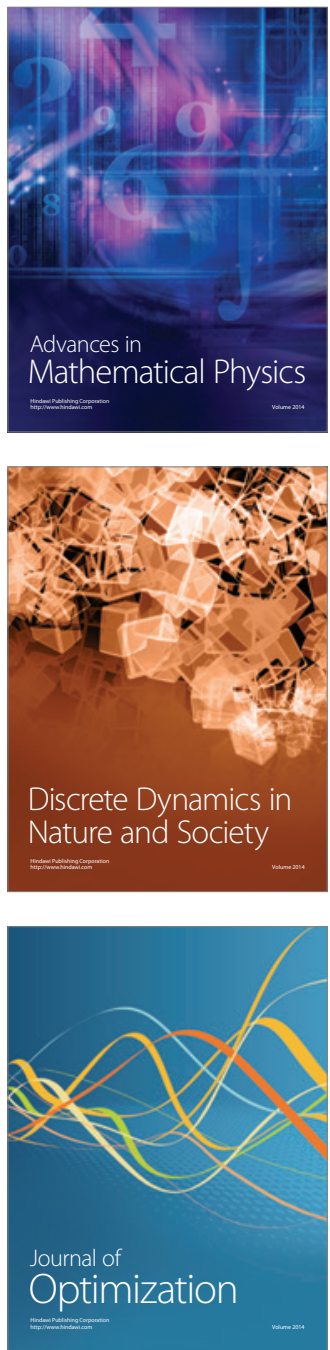